Supporting information

\title{
Enzymatic glucose-oxygen biofuel cells for highly efficient interfacial corrosion protection
}

Aleksandar Karajićl,2, Pascal Merzeau ${ }^{1}$, Emmanuel Suraniti ${ }^{2}$, Sébastien Gounel ${ }^{1}$, Christèle

Jaillet ${ }^{1}$, Alexander Kuhn ${ }^{2 *}$, Nicolas Mano ${ }^{1 *}$.

${ }^{1}$ Centre de Recherche Paul Pascal (CRPP), CNRS UMR 5031, Univ. Bordeaux, 115 Avenue du Docteur Schweitzer, 33600 Pessac, France.

${ }^{2}$ Univ. Bordeaux, CNRS UMR 5255, Bordeaux INP, ENSCBP, 16 avenue Pey-Berland, 33600 Pessac, France.

Corresponding author* E-mail: nicolas.mano@crpp.cnrs.fr

Corresponding author*E-mail: kuhn@enscbp.fr 
Scheme S1.

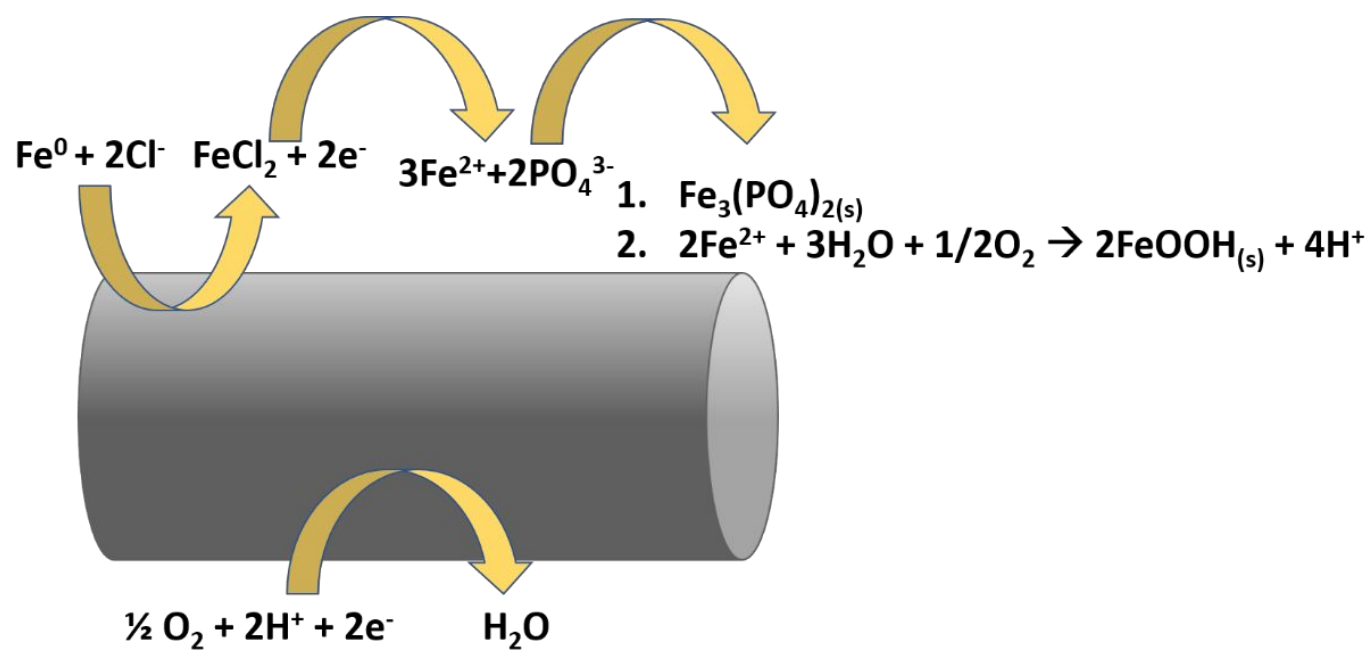

Scheme S1. Proposed mechanism for the corrosion of a pure iron object in a phosphate-buffer saline solution (20 mM Phosphate buffer $+140 \mathrm{mM} \mathrm{NaCl})$ at $\mathrm{pH}$ 7.2.

Scheme S2. 


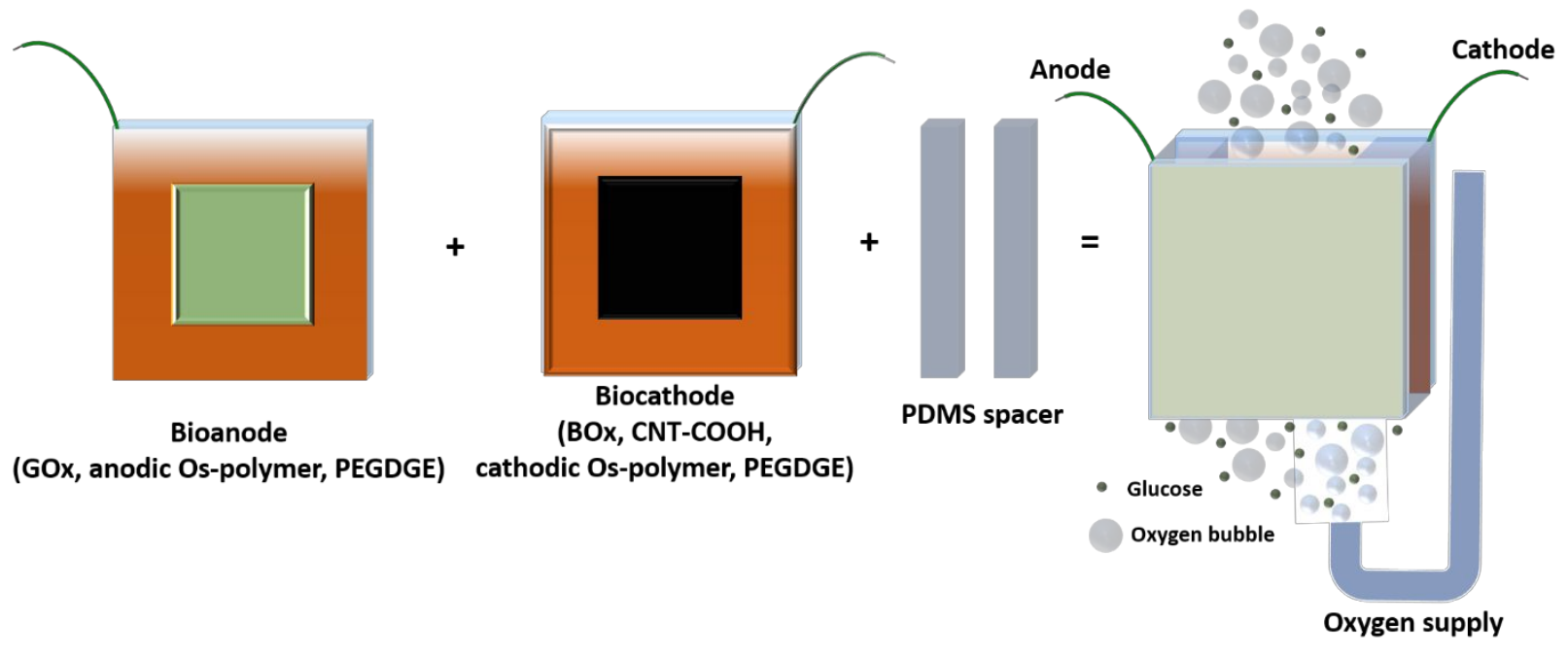

Scheme S2. A schematic representation of the key-steps in the fabrication of the glucose/oxygen biofuel cell. The thickness of the PDMS spacer was $7 \mathrm{~mm}$.

Figure S1. Low power boost converter

A low power boost converter has been modified with the $5 \mathrm{M} \Omega$ potentiometer in series with 8.2 $\mathrm{M} \Omega$ by removing the resistors $\mathrm{R}_{\mathrm{ov} 1}$ and $\mathrm{R}_{\mathrm{ov} 2}$ from their original positions.

The resistance at which the potentiometer needs to be set in order to achieve $2.3 \mathrm{~V}$ at the output of the boost converter is calculated by using the following formula:

$$
V B A T_{-} O V=\frac{3}{2} V B I A S\left(1+\frac{R_{O V 2}}{R_{O V 1}}\right)
$$

where: $R_{O V 1}+R_{O V 2}=13 M \Omega$

$$
\begin{aligned}
& R_{O V 1}=8.2 M \Omega+\alpha \times 5 M \Omega \\
& R_{O V 2}=5 M \Omega x(1-\alpha) \\
& \alpha: 0-1
\end{aligned}
$$$$
V B I A S=1.21 \mathrm{~V}
$$

$V B A T_{-} O V$ - voltage required by a specific application (the voltage of $2.3 \mathrm{~V}$ was used in this study). 


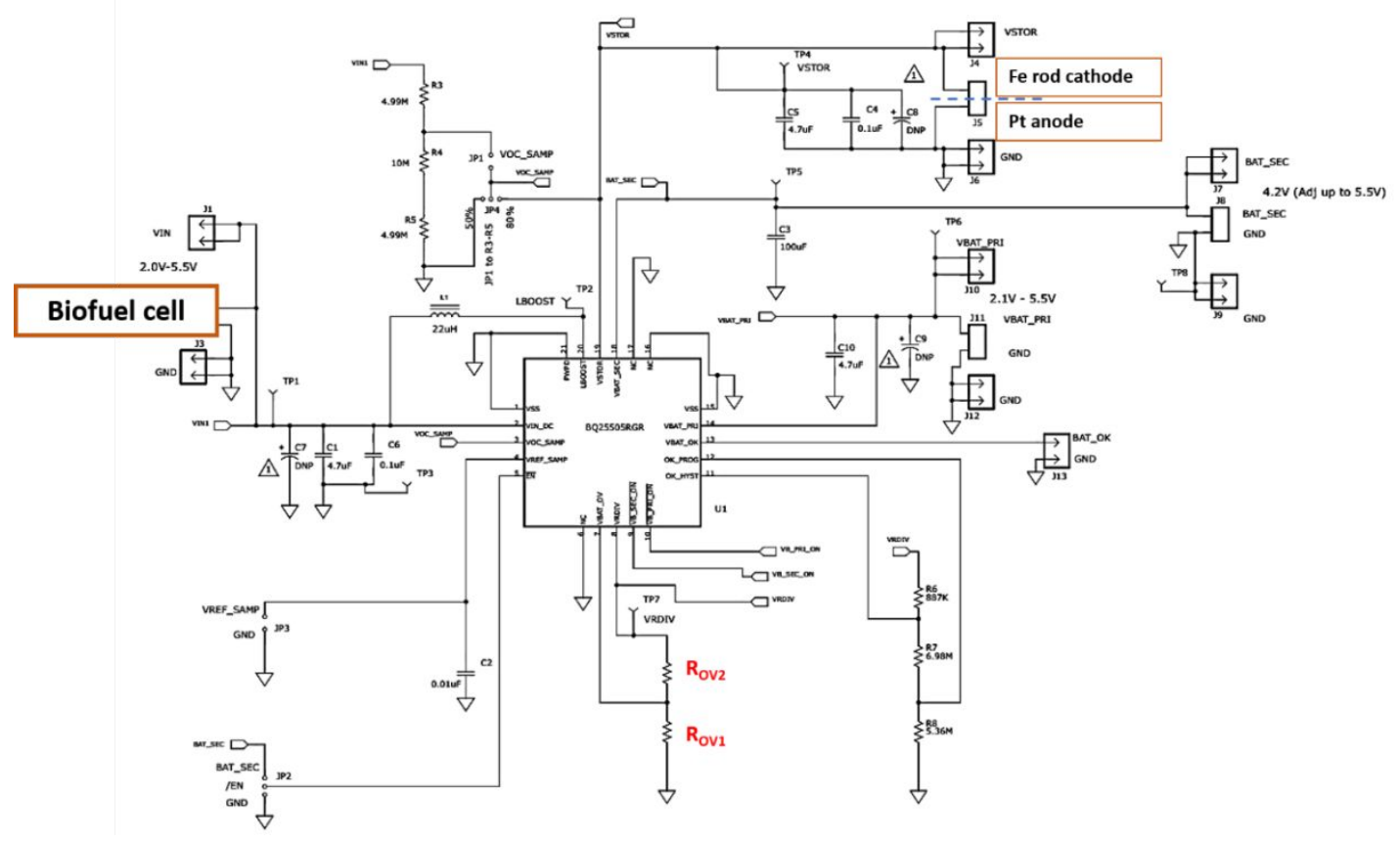

Figure S1. A circuit diagram showing the scheme of the boost converter used in this work. A $5 \mathrm{M} \Omega$ potentiometer in series with a $8.2 \mathrm{M} \Omega$ resistor is introduced into the circuit instead of the original resistors

$\mathrm{R}_{\mathrm{OV} 1}$ and $\mathrm{R}_{\mathrm{OV} 2}$. The original electronic diagram of the boost converter can be downloaded from: http://www.ti.com/lit/ug/sluuaa8a/sluuaa8a.pdf.

Among the two preadjusted values of the Maximum Power Point (i.e. $50 \%$ and $80 \%$ of the OCV), we have chosen to operate at $50 \%$ of the OCV. This adjustment has been done by an adequate positioning of the JP4 jumper on the electronic board.

\section{S2. Potentiodynamic polarization experiment}




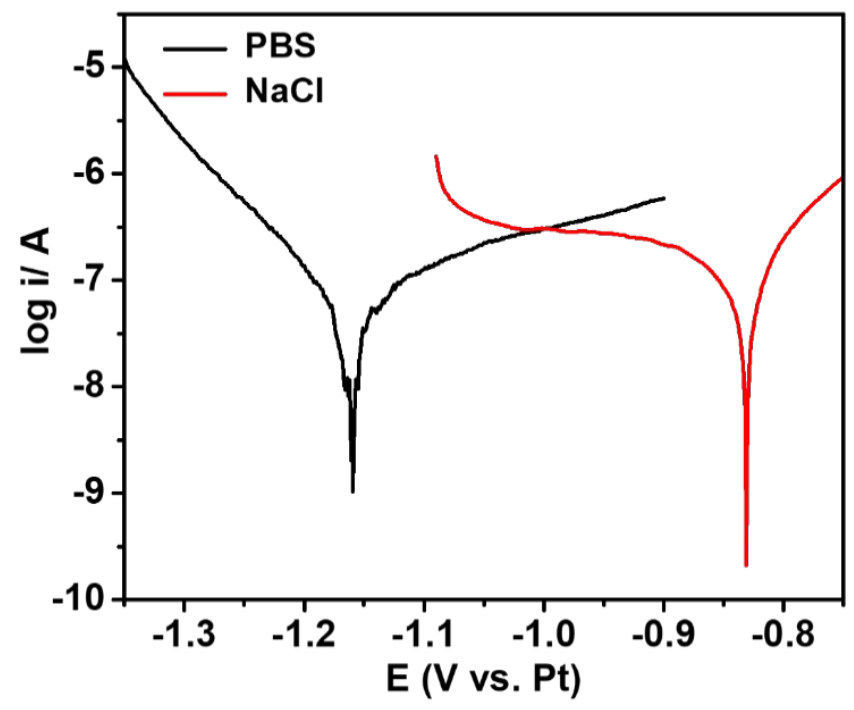

Figure S2. Tafel plots recorded in PBS (20 mM PB + $140 \mathrm{mM} \mathrm{NaCl}$; $\mathrm{pH}$ 7.2, black curve) and $140 \mathrm{mM}$ $\mathrm{NaCl}$ (red curve) solutions at a scan rate of $1 \mathrm{mV} \cdot \mathrm{s}^{-1}$ in a two-electrode electrochemical system consisting of a Fe rod as working and $\mathrm{Pt}$ counter/reference electrodes. 

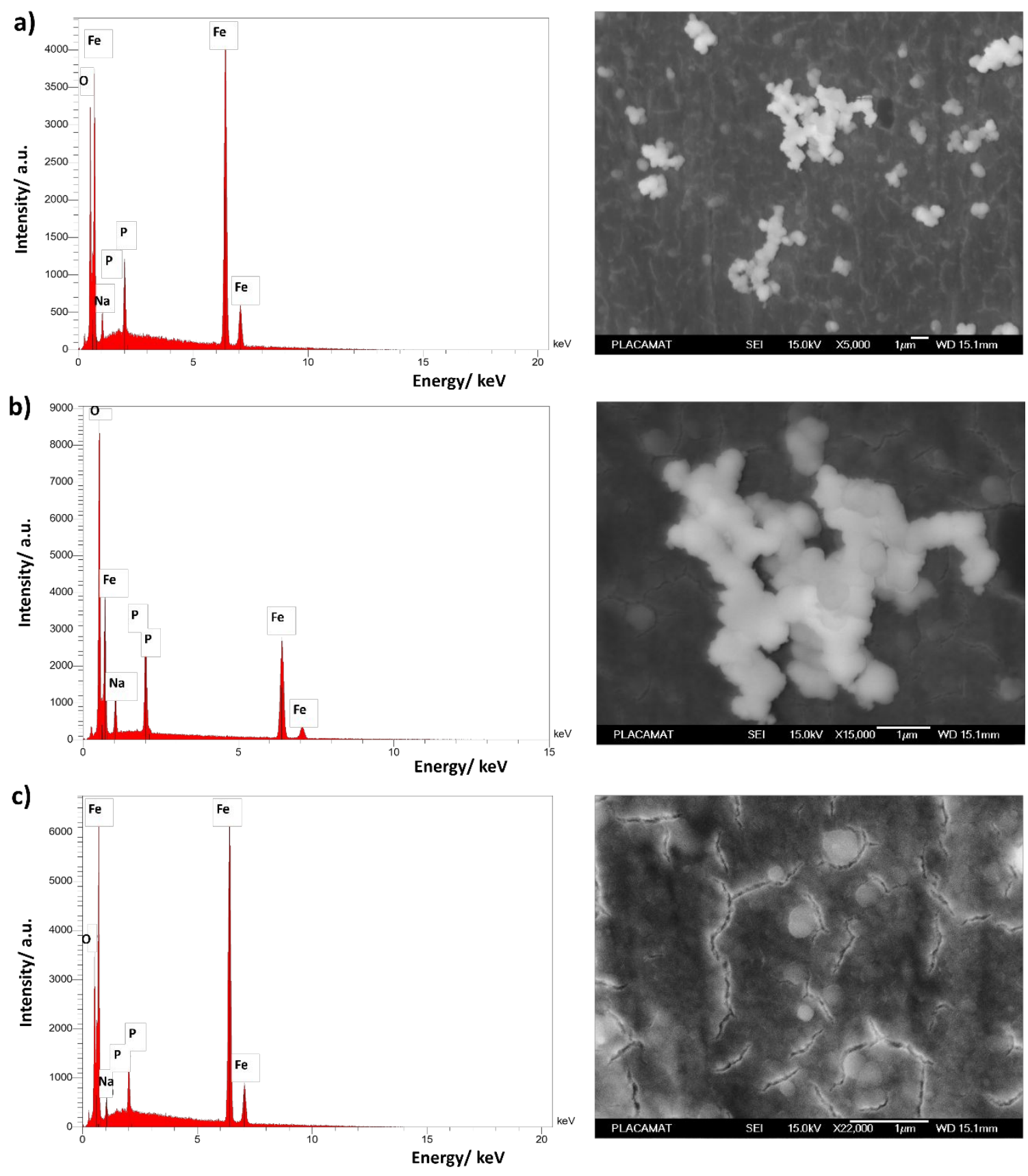

Figure S3. EDS analysis of the corroded iron surface: low-magnification image (a); magnification of a surface corrosion agglomerate (b) and a corrosion film (c).

\section{S4. Corrosion evolution study}


a)

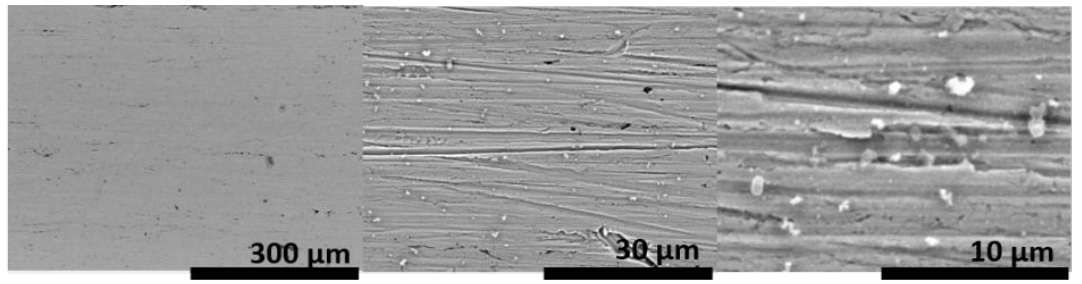

b)

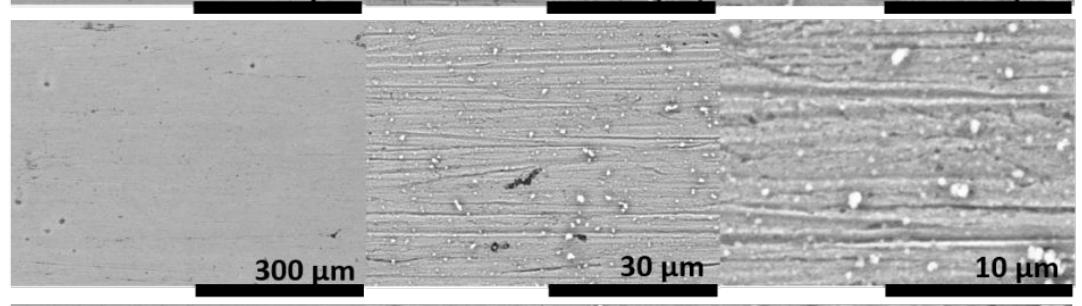

c)

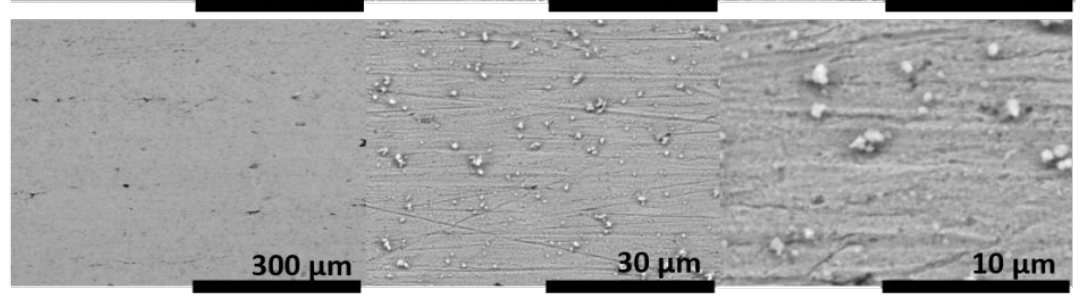

d)

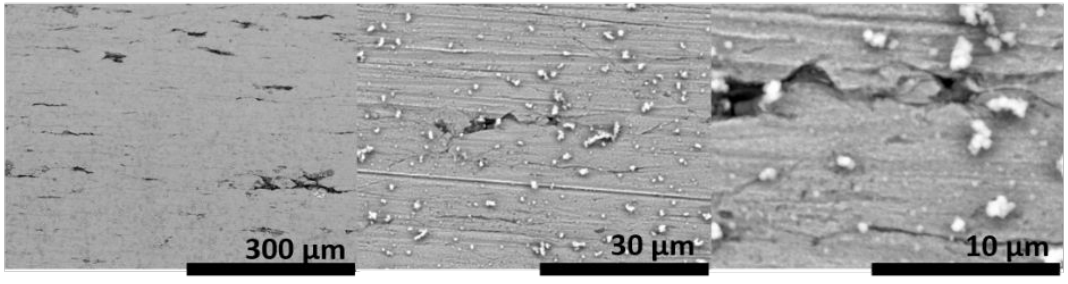

e)

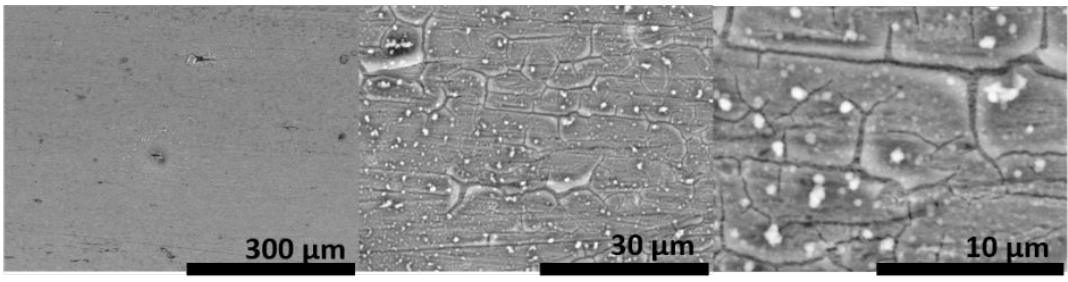

f)

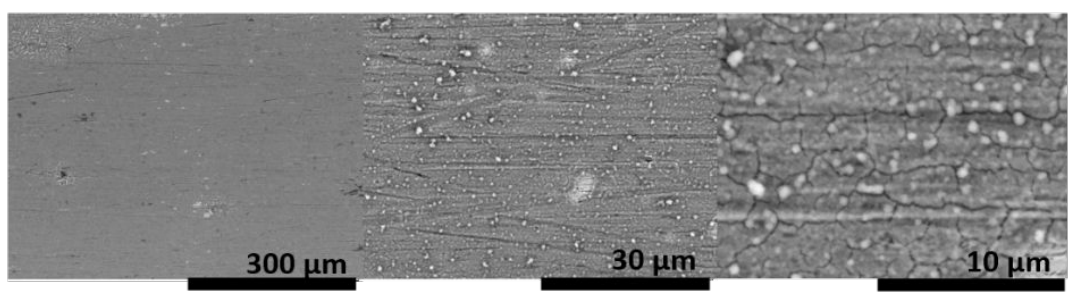

Figure S4. SEM images obtained at different magnifications for a control sample that was left to corrode in PBS (20 mM PB + $140 \mathrm{mM} \mathrm{NaCl}$; pH 7.2) solution for 3min (a); $1 \mathrm{~h} \mathrm{(b);} 2 \mathrm{~h} \mathrm{(c);} \mathrm{3h} \mathrm{(d);} \mathrm{4h} \mathrm{(e)} \mathrm{and} \mathrm{5h}$ (f). 
S5. Electrochemical impedance spectroscopy (EIS) measurement

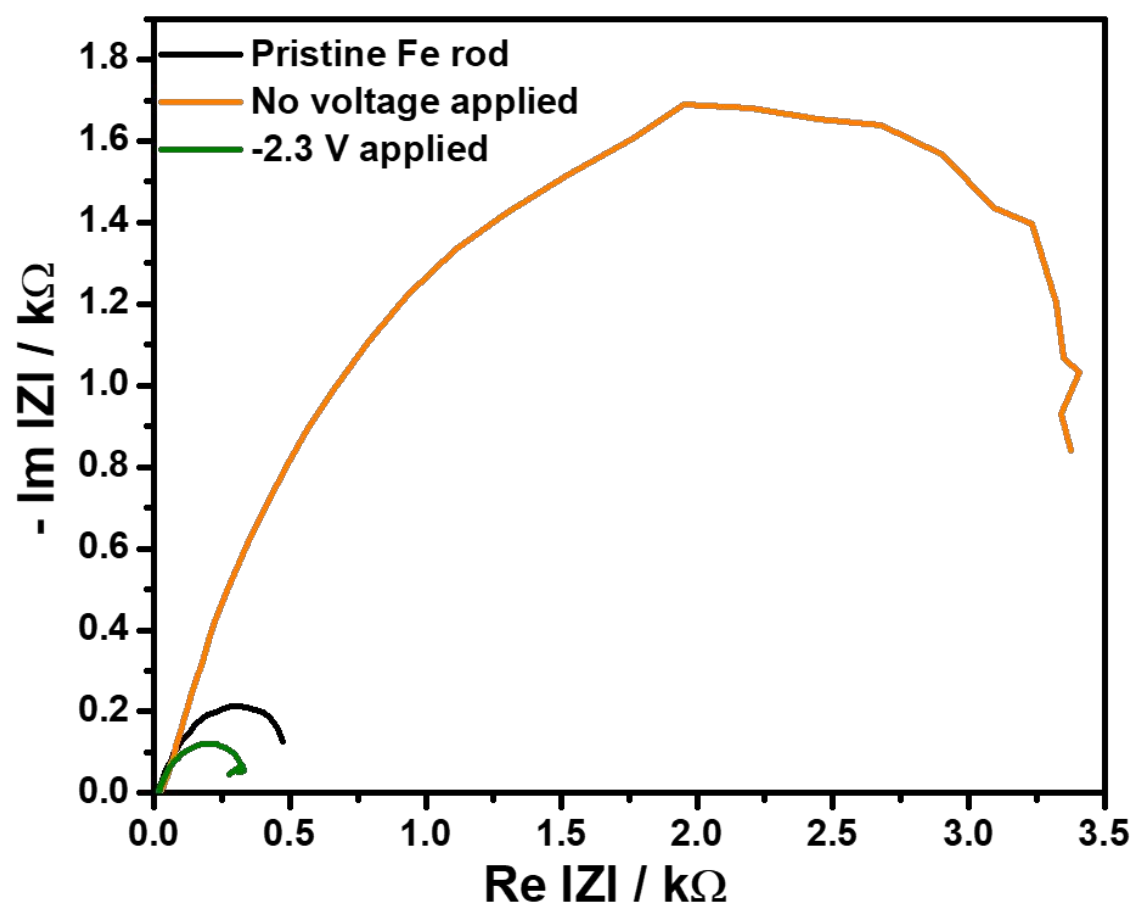

Figure S5. Nyquist plots obtained for pristine metal (black), a control without protection (orange) and a Fe rod that was exposed to $-2.3 \mathrm{~V}$ ( $v s$. Pt pseudo-reference electrode) for $4 \mathrm{~h}$. 
S6. Optimization of the ratio between BOD/Os-redox polymer/PEGDGE hydrogel and MWCNT-COOH

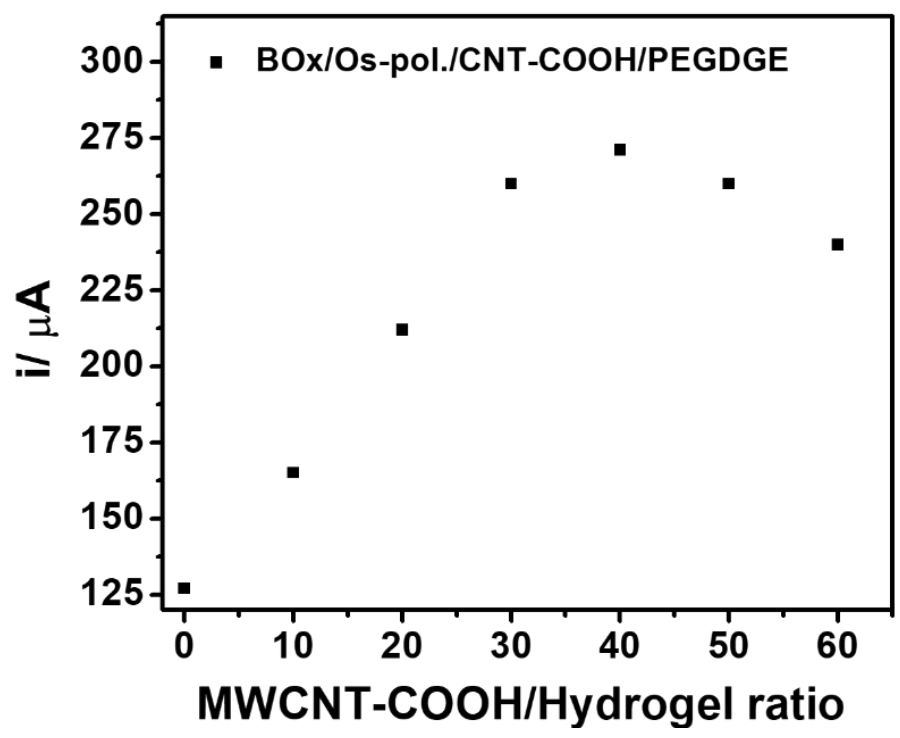

Figure S6. Optimization of the MWCNT-COOH/enzymatic hydrogel ratio. The enzymatic hydrogel loading was kept at $108 \mu \mathrm{g} . \mathrm{cm}^{-2}$ while the amount of MWCNT-COOH was changed in the range from 10 to $60 \mathrm{wt} \%$. Cyclic voltammograms were recorded in an oxygen saturated $\mathrm{PBS}$ buffer at $\mathrm{pH} 7.2,37.5^{\circ} \mathrm{C}$ and $500 \mathrm{rpm}$ in a three-electrode set-up. The composite modified glassy-carbon RDE served as a working electrode, while $\mathrm{Pt}$ and $\mathrm{Ag} / \mathrm{AgCl}$ were used as counter and reference electrodes, respectively. 